\title{
Bases y Lineamientos de un Código Tributario actual(")
}

\section{Foundations and Guidelines of a current Tax Code}

\begin{abstract}
Resumen: El autor expone los puntos clave para una futura codificación tributaria. Reconoce la importancia de abordar los principios jurídicos y la dogmática tributaria desarrollada hasta el momento, pero advierte que deben ser de igual importancia los nuevos problemas han surgido en el área. Además, señala la importancia de una mejora en la calidad de gestión administrativa para la correcta aplicación del Derecho Tributario.
\end{abstract}

Palabras Clave: Código Tributario - Reforma - Estado - Derecho Tributario

\begin{abstract}
The author expose the key points for future tax codification. He recognize the importance of address the legal principles and the dogmatic taxation developed so far, but he warns that they must be of equal importance the new problems have arisen in the area. In addition, he points out the importance of an improvement in the quality of administrative management for the correct application of Tax Law.
\end{abstract}

Keywords: Tax Code - Reform - State - Tax Law

\section{Introducción}

Los códigos latinoamericanos concebidos durante el Siglo XX (como el código peruano que acaba de cumplir cincuenta años) cumplieron un importante rol para la consagración de los principios jurídicos aplicables a las relaciones entre el fisco y el contribuyente. La ley tributaria reflejó entonces, de manera adecuada, el desarrollo doctrinario referido al siempre delicado equilibrio entre las garantías individuales y la eficiencia de la actividad recaudadora. Ya en el nuevo siglo, es inevitable adaptar aquellos códigos a una realidad que ha cambiado de manera significativa. De otro lado, la experiencia demuestra que

(*) Socio fundador de Bulit Goñi \& Tarsitano, Abogados y Consultores. Profesor en Temas Tributarios de la Universidad de Buenos Aires y de la Universidad Católica de Argentina, fundador de la Maestría en Derecho Tributario de la UCA que actualmente dirige. Correo electrónico: info@albertotarsitano.com

$\left.{ }^{(* *}\right)$ Nota del Editor: El artículo fue recibido el 15 de noviembre de 2016 y aprobada su publicación el 03 de diciembre del mismo año. 


\section{Bases y Lineamientos de un Código Tributario actual Foundations and Guidelines of a current Tax Code}

la lucha por disminuir los déficits fiscales y superar las crisis económicas han reforzado el rol de las Administraciones fiscales, en detrimento de la vigencia efectiva de ciertos principios generales consagrados por la dogmática tributaria. Por ello, es necesario proponer un modelo de código que provea los instrumentos acordes a los avances tecnológicos, y al mismo tiempo afiance una relación jurídica de pleno derecho, en la que se fijen con precisión las obligaciones y deberes del contribuyente, y se eliminen los privilegios o las prerrogativas del Fisco.

\section{Bases y lineamientos de un Código Tributario actual}

Hemos respondido con entusiasmo a la invitación de la Pontifica Universidad Católica de Perú, para participar en las Jornadas de homenaje a los cincuenta años de la sanción del Código Tributario, celebradas en Lima, los días 19 y 20 de septiembre de $2016^{(1)}$.

Con entusiasmo, pues el antecedente merece ser recordado por su correspondencia con los valores democráticos, y por la oportunidad que brinda para volver a plantear la necesidad de que aquellos códigos concebidos en la América Latina del siglo pasado (nos referimos a la codificación parcial) encaren de una manera orgánica los desafíos o las demandas de la realidad y los actores del siglo XXI: las posibilidades tecnológicas, la complejidad creciente del sistema tributario, los cambios en las Administraciones tributarias, y la aparición en escena de un contribuyente multinacional y un fisco global.

Ya en las I Jornadas Latinoamericanas de Derecho Tributario (Montevideo, 1956), entre las conclusiones del Tema
I: "Autonomía del derecho tributario" se consignó: "5. Las normas jurídicas - tributarias sustanciales, formales y procesales, deben ser agrupadas sistemáticamente en cuerpos jurídicos orgánicos".

Pero fueron en las II Jornadas (México, 1958), donde se trató el Tema III: "La codificación del derecho tributario", y se recomendó: "2. Que se establezcan códigos tributarios en cada uno de los países latinoamericanos que fijen sistemáticamente y ordenadamente los principios generales del derecho tributario y que incluyan las normas procesales que garanticen los derechos individuales y permitan la adecuada aplicación de aquéllos. 3. Que esos códigos ofrezcan caracteres de permanencia, certeza y claridad, a fin de asegurar la estabilidad y conocimiento de las situaciones jurídicas que los mismos reglamente".

La codificación siguió siendo recomendada en las XVI Jornadas (Lima, 1993); en las XX Jornadas (Salvador de Bahía, 2000), donde se decide "sugerir a los países de la región mantener el Modelo de Código Tributario para América Latina como base de sus códigos y leyes relativos a la materia en todos los niveles de gobierno, sin perjuicio de efectuar las adaptaciones y actualización que se consideren necesarias, pero preservando la orientación de este Modelo, en resguardo de

(1) En la Argentina no existe un código tributario nacional. Pero está la ley 11683 sancionada a fines del año 1932 bajo el nombre de "Procedimiento para la aplicación, percepción y fiscalización de impuestos", con la finalidad de acompañar los cambios impositivos derivados de la crisis de los años 30. A partir de la reforma del año 1946 introducida por el Decreto 14.341/46, ratificado por la ley 12.922, el ordenamiento fue adquiriendo mayor expansión y rebasó su carácter procesal para ocuparse de cuestiones relativas al derecho tributario sustantivo y sancionatorio.

En sus orígenes, constituyó un intento temprano y eficiente para superar la dispersión de normas existentes y sistematizar la relación jurídica tributaria en sus aspectos generales, administrativos y procesales.

Desde entonces, las sucesivas reformas fueron acompañando la evolución del sistema tributario nacional (y su creciente complejidad) con cierta presentación metódica, pero nunca se concretó el anhelo de crear un código tributario nacional, orgánico y sistematizado. Existieron valiosos intentos codificación parcial, como el anteproyecto del año 1942, elaborado por el doctor Carlos M. Giuliani Fonrouge, y luego, en 1963, el proyecto redactado por el mismo autor. A nivel local se destaca el proyecto de codificación completa de Dino Jarach para la Provincia de Buenos Aires (1947), aprobado por la legislatura en 1948, y que sirvió de modelo al resto de las provincias. 


\section{Alberto Tarsitano}

los aludidos principios de la tributación"; y finalmente en las XXV Jornadas (Cartagena, 2010).

Un impulso fuerte al movimiento codificador en América Latina fue la redacción del Modelo de Código Tributario para América Latina (MCTAL) de 1967, auspiciado por la OEA y el BID. Sus autores, los maestros Giuliani Fonrouge, Gomes de Sousa y Valdés Costa, declararon que se proponían "fijar posición acerca de las grandes cuestiones", y la primera de ellas era "consagrar principios jurídicos aplicables a las relaciones entre el fisco y el contribuyente, armonizando la eficacia administrativa con las garantías individuales consagradas en las respectivas constituciones" (ver "Exposición de Motivos", ap. "Consideraciones Generales").

Un código moderno debe actuar en dos escenarios. Porque que es tan imperioso dar respuesta a los problemas nuevos como seguir lidiando con los problemas viejos (pero no anacrónicos), que son maltratados u omitidos en la normativa vigente. $\mathrm{O}$ buscar la forma de asegurar valores y procedimientos de escasa vigencia práctica, víctimas de los males que suelen afectar la región: el autoritarismo, el populismo y la corrupción. Una evaluación en este terreno de cincuenta años vida codificada seguramente arrojaría en Perú, como en la Argentina, avances y retrocesos.

No hace falta reiterar lo que tantas veces se ha dicho sobre la importancia de un ordenamiento metódico, simple, claro y completo, para mejorar la calidad de la gestión administrativa, inducir el cumplimiento espontáneo, disminuir su costo, y elevar la tutela jurisdiccional, así como para afianzar los valores de certeza, seguridad jurídica y confianza legítima de los contribuyentes. Pero también es imprescindible reiterar que la redacción del mejor código no alcanza por sí misma para cumplir esos propósitos.

La dialéctica entre norma y realidad debería contribuir a que la experiencia acumulada estimule los mecanismos para asegurar que aquellos principios y nociones generales tan conocidos, reiterados y mentados en los ámbitos académicos, adquieran eficacia práctica, con un aceptable nivel de concreción. La letra de la ley, por más que recepte los conceptos arropados por la dogmática del derecho o la autonomía del derecho tributario, sirve de muy poco si los entes públicos no tienen la calidad o preparación adecuada o actúan con desvío o abuso de poder. Por tal motivo el diseño de las normas debería preocuparse por la competencia y formación de los organismos encargados de aplicarlos, y crear los mecanismos de control necesarios, asegurando que el controlado no se controle a sí mismo.

Ni si quiera así se asegura nada. Pues, en definitiva, el siempre el delicado equilibrio entre el Estado y el individuo, es una lucha eterna entre las prerrogativas y las libertades, entre los poderes y las garantías, que no se resuelve en la letra de los textos, ni siquiera en las instituciones de alguna manera siempre influidas por los poderes de turno, sino en los valores, la cultura y la educación del pueblo.

El derecho constituye la más refinada herramienta de organización social. El estado social y democrático de derecho es su mejor expresión. Y si hay un derecho democrático y social ese es el derecho tributario, quien, a través del deber de contribuir en función del principio de la capacidad, presupuesto del poder de imposición, pero al mismo tiempo garantía individual, hace posible alguna redistribución de la riqueza y la posibilidad de satisfacer las necesidades mínimas de los más pobres. El derecho a la salud, a la educación, a la alimentación, o todo estándar mínimo que acompaña la vida digna, no deberían ser abstracciones de las Constituciones y Tratados sobre Derechos Humanos, sino el derecho subjetivo que se haga valer antes los gobiernos, pues hubo un universo de obligados que ha financiado al universo de los carenciados. He aquí el punto de encuentro entre el ingreso y el gasto público, que deben ser considerados con una visión unitaria por Derecho Financiero como disciplina autónoma.

Toda reforma que haga pie en los principios generales del derecho tributario y en las garantías individuales debe partir de la Constitución Nacional, no sólo porque la división de poderes constituye la premisa del 
Bases y Lineamientos de un Código Tributario actual Foundations and Guidelines of a current Tax Code orden jurídico formal de la Hacienda Pública, sino porque no existe un mejor instrumento para conciliar los valores e intereses subyacentes a la relación jurídico tributaria.

El deber de contribuir encuentra su cauce en la relación jurídica tributaria entendida como "relación de derecho", según la difundida visión de Hensel que cumplirá pronto un siglo. Allí los contribuyentes y la Administración se someten por igual al imperio de la ley, y se elimina la discrecionalidad y los privilegios del Estado. Por oposición ideológica, la concepción de la "relación de poder" marca el predominio del Estado sobre el individuo y su libertad. Como nos enseñó el maestro Eusebio, la codificación conlleva la elección del molde o esquema conceptual del tributo y remite a una forma de relación jurídica entre el Estado y los ciudadanos. El tipo de relación jurídica influyen de manera abierta o sutil los modelos de codificación. Un ejemplo negativo, lo constituye el Modelo de Código de CIAT del año 1997, que tantas reacciones levantó en los ámbitos ilustrados, al extremo que el ILADT le dedicó al tema la XXV Jornadas de Bahía (año 2000). A sido un signo saludable que el nuevo Modelo presentado por el CIAT en el año 2015 ha superado aquel cuestionado antecedente, elaborando un valioso documento que puede servir de inspiración a las futuras codificaciones de la región.

Toda reforma debería establecer su orientación respondiendo a un grupo preguntas en apariencia sencillas: ¿Qué interés se pretende proteger? ¿la decisión normativa influirá sobre los comportamientos de los contribuyentes y administraciones fiscales? ¿Es deseable o justa esa influencia? ¿Hay conflicto con el régimen jurídico general? ¿A qué contribuyente nos dirigimos: ¿a los individuos, a la pequeña empresa de Chiclayo o a la gran empresa multinacional? ¿Es posible un código "eficiente" donde todos ganen? Esta última posibilidad podría ser negada bajo el método de análisis económico del derecho como ejercicio para ponderar las decisiones de la política legislativa, ya sea bajo la noción de "eficiencia" economicista de Pareto (favorecer a unos y ser neutral sobre otros), Coase (los beneficiados negocian el costo con los perjudicados) o Kaldor, Hicks (los beneficiados compensan a los damnificados).

Las propuestas y lineamientos que aquí se presentan deberían pasar a formar parte de un nuevo ordenamiento denominado como "Ley General Tributaria" o "Código Tributario Nacional", dando cuenta del contenido que excede los aspectos procesales para recalar, con orden metódico, en los temas generales, y en los aspectos administrativos, jurisdiccionales y contravencionales.

Nuestro pensamiento aparece guiado por la ponderación crítica de la ley argentina, introduciendo con cierto detalle aquellos agregados o modificaciones que deberían ser objeto de la política y técnica legislativa, con la introducción de cuestiones relevantes tales como, entre, muchas otras, el alcance de la cláusula general contra el abuso de la ley y la simulacion, el acuerdo conclusivo sobre los hechos en sede administrativa, la protección del derecho a la privacidad incluyendo la reserva de cierta información, la adecuación de los instrumentos informáticos a los cánones procesales, el derecho a la no autoincriminación, la extensión de la competencia del Tribunal Fiscal de la Nación, la acción de daño por la responsabilidad del Estado y sus funcionarios, y la acción declarativa directa de inconstitucionalidad.

Como puede advertirse, estas reflexiones trascienden el ámbito al que fueron dirigidas originariamente, pues la estructura común que asumen los códigos tributarios en América Latina vuelve estos temas universales y a menudo urgentes.

La tarea aborda muchos temas, algunos viejos conocidos y otros cuya potencialidad apenas se vislumbra, desde el poderoso faro de luz que ilumina el puerto de llegada: la doctrina reunida en las distintas Jornadas del Instituto Latinoamericano de Derecho Tributario (ILADT) y el Modelo de Código Tributario para América Latina (MCTAL).

Finalmente, nuestro homenaje y reconocimiento al Código Tributario de 1966 debe ir acompañado al emocionado recuerdo de los hombres que lo gestaron, entre ellos el profesor Enrique Vidal Cárdenas, fuente 
Alberto Tarsitano

de inspiración y enseñanza e integrante de la generación de hombres sabios que forjó la doctrina latinoamericana.

\section{Conclusiones}

- Es necesario asegurar en una futura codificación, la vigencia práctica de los principios jurídicos acuñados por la dogmática tributaria.

- Un ordenamiento metódico, simple, claro y completo, mejora la calidad de la gestión administrativa al tiempo que afianza la seguridad jurídica.

- La letra de la ley, por más que recepte los conceptos arropados por la dogmática tributaria, sirve de muy poco si no se mejora la calidad los entes públicos o no existen los mecanismos de control institucional adecuados.
- Toda codificación debe partir de la Constitución Nacional, pues:

(i) No existe un mejor instrumento compensador de intereses que el deber de contribuir, basado en la capacidad contributiva, en su doble expresión de legitimación del Estado y garantía individual

(ii) La división de poderes constituye la primera garantía del derecho del contribuyente.

- El tipo de relación jurídica influye de manera más o menos abierta o sutil los modelos de codificación. La experiencia nos demuestra, ya entrado el Siglo XXI, que "la relación de derecho" ha perdido terreno en beneficio de "la relación de poder", y se comprueba, con evidente retroceso, que el valor asignado a la tutela de la renta pública merece más consideración que las garantías individuales.

- La estructura que asumen los códigos tributarios en América Latina y la realidad a la que atienden, vuelven estos temas comunes y urgentes. 